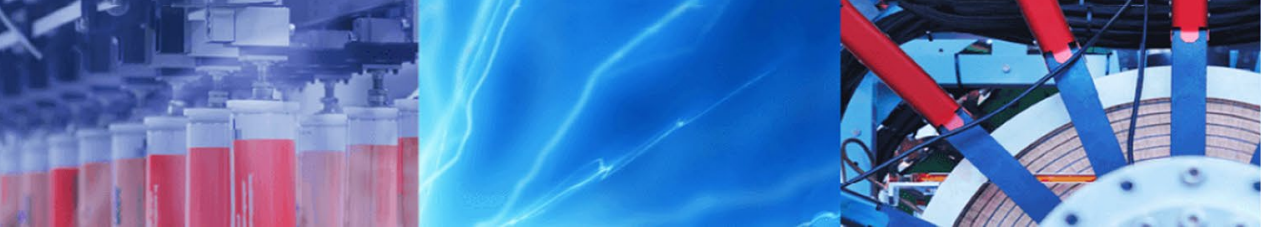

Research Article

\title{
Specific chemical incorporation of L-DOPA and functionalized L-DOPA-hyaluronic acid in Candida antarctica lipase: creating potential mussel-inspired bioadhesives
}

\author{
Johana Jaramillo' · Ivan Rodriguez-Oliva' ${ }^{1}$ Olga Abian ${ }^{2,3,4,5,6} \cdot$ Jose M. Palomo $^{1}$ (1)
}

Received: 24 June 2020 / Accepted: 17 September 2020 / Published online: 24 September 2020

(c) Springer Nature Switzerland AG 2020

\begin{abstract}
Mussel adhesives proteins have been extensively studied as a promising alternative in bioadhesives due to their ability to provide durable anchoring under different surfaces in seawater. These charasteristics have been attributed to the presence of the reduced catechol form, 3,4-dihydroxyphenylalanine (DOPA) of its structure. However, its practical applications have been limited due to drawbacks with natural extraction. Here, a novel method have been described for site-specific chemical incorporation of L-3,4-dihydroxyphenylalanine methyl ester (L-DOPAME) into proteins, in particular Candida antartica fraction B (CAL-B) lipase. Two strategies were followed, direct conjugation of DOPA at the C-terminus on the surface of the protein, and protein conjugation with tailor-made glycopolymers (DOPA-hyaluronic acid (HA) polymers) at the $\mathrm{N}$-terminus. In all cases, the characterization of the new DOPA-proteins was carried out using circular dichroism, fluorescence or mass spectrometry. An improvement in the activity (in some cases more than 2 times) or the thermostability of CAL-B (with a half live 4 fold greater in some cases) was found by the incorporation of DOPA molecules. These DOPA-proteins showed excellent underwater covalent adhesive ability on amino functionalized surfaces in aqueous media compared to other modified [e.g. tyrosine modified (TYR)] CAL-B proteins. At pH 8.5, CALB-DOPA proteins were completely adsorbed after 90 min of incubation, whereas about $10 \%$ of CALB-HA or CALB-TYR proteins were adsorbed at the same time. Native CAL-B adsorption was not observed. These results suggest a potential application of these DOPA-proteins as bioglues or bioadhesives for practical underwater applications.
\end{abstract}

Electronic supplementary material The online version of this article (https://doi.org/10.1007/s42452-020-03545-w) contains supplementary material, which is available to authorized users.

$\checkmark$ Jose M. Palomo, josempalomo@icp.csic.es | 'Department of Biocatalysis, Institute of Catalysis (CSIC), Marie Curie 2. Cantoblanco. Campus UAM, 28049 Madrid, Spain. ${ }^{2}$ Instituto Aragonés de Ciencias de la Salud (IACS), Zaragoza, Spain. ${ }^{3}$ Fundación Instituto de Investigación Sanitaria de Aragón (IIS Aragon), Zaragoza, Spain. ${ }^{4}$ Instituto de Biocomputación y Física de Sistemas Complejos, Joint Units IQFR-CSIC-BIFI, and GBsC-CSIC-BIFI, Universidad de Zaragoza, Zaragoza, Spain. ${ }^{5}$ Centro de Investigación Biomédica en Red en el Área Temática de Enfermedades Hepáticas y Digestivas (CIBERehd), Madrid, Spain. ${ }^{6}$ Departamento de Bioquímica y Biología Molecular y Celular, Universidad de Zaragoza, Zaragoza, Spain. 


\section{Graphic abstract}

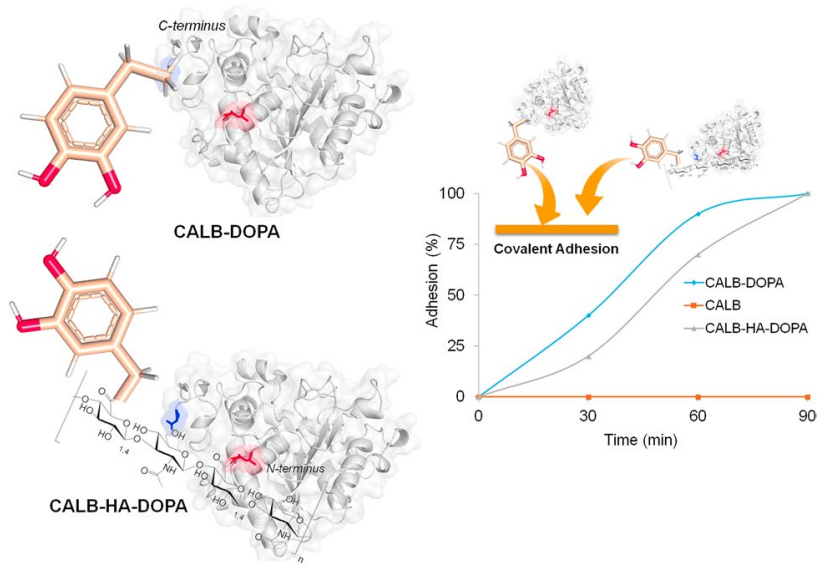

Keywords Mussel-inspired bioadhesives · DOPA · DOPA-polymers - Chemical modification · Hyaluronic acid · Lipase

\section{Introduction}

An adhesive is a substance capable of holding two surfaces together in a strong and permanent manner [1]. The raw materials used as adhesives are mainly polymeric materials, both natural and synthetics [2]; thus, depending on their origin source, adhesives can be divided in two main categories: Bio-based adhesives and Synthetic Adhesives [3-7]. In general, bio-based adhesives present direct advantage in environmental terms, due to the absence of toxicity for both, ecosystem and human health. Moreover, their origin from renewable resources results in lower net $\mathrm{CO}_{2}$-emissions compared to petroleum-based adhesives [8]. However, most of them exhibit poor water resistance and, sometimes, render too high costs to successfully compete in the adhesive industry [9]. Synthetic adhesives, on the other hand, have bulk cohesive strength much greater than natural underwater adhesives. Nevertheless, their adhesion capacity eventually fails due to the poor interfacial adhesion in the presence of water [10]. In consequence, wet adhesion remains the main challenge of future developments [11], specially for medical applications as these also must be, among other things, non-toxic, biocompatible, biodegradable and easy to manipulate [12]. Many different approaches have been proposed in order to solve the problem of wet adhesion. One of the most remarkable has been the study of natural mussel adhesive proteins (MAPS) from the adhesive plaques of Mytilus holdfast or byssus [13], due to their superior properties including biocompatibility, biodegradability and surface-independent adhesiveness even in a wet environment [14]. Over the last decades, several studies have attributed the MAPS coating and adhesive properties to the abundance of $\mathrm{L}-3,4$-dihydroxyphenylalanine (L-DOPA); a catecholamine whose formation is derived from the hydroxylation of the aromatic ring of tyrosine residues [15]. In this way, MAPS closer to the adhesion interface have shown a higher amount of L-DOPA residues [16] and, on the contrary, the absence of L-DOPA in MAPS composition has been associated with the loss of the adhesion capacity [17]. Additionally, other studies have reported that the presence of the catechol amino-acid, DOPA, enables the binding in both organic and inorganic surfaces through $\mathrm{H}$-bond or metal reversible (non-covalent) or irreversible (covalent) interactions due to the diverse chemical capabilities of the catechol; reaffirming in this way the dominant role of the catechol chemistry in the adhesion and crosslinking of MAPS (Fig. 1) [18].

However, despite all this research, the practical applications of MAPS still remain restricted due to the lack of understanding around how L-DOPA interacts in most of the surfaces and how other abundant components in Mytilus edulis foot proteins (Mefps), such as lysine, interact in the wet adhesion mechanism $[19,20]$. In the same way, although the extraction of MAPS from Mytilus species has been done before, their widespread commercial use has been extremely limited and a cost-ineffective process; not only because to produce minimum quantities of adhesive high number of mussels specimen are required [21], but also because the chemical extraction process does not always yield pure or individual adhesive proteins [22]. Alternatives such as redesigning hybrid type MAPS, fp-151, in Gram-negative bacterium Escherichia coli, has been described as an alternative in order to overcome the 


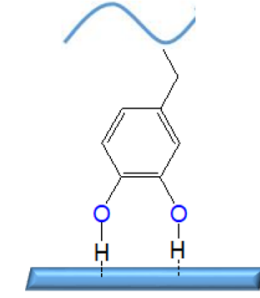

Adsorption to surfaces by $\mathrm{H}$-bond $\mathrm{pH}$ 2-5

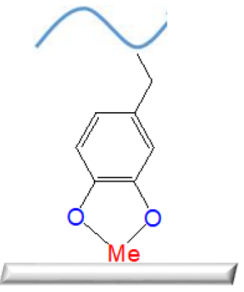

Adsorption to metal / metal oxide surfaces
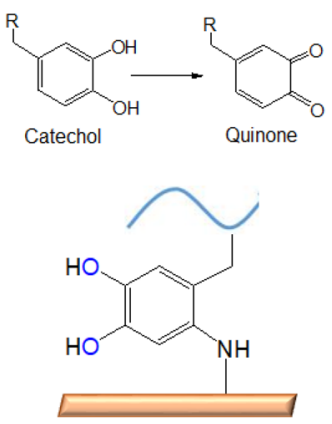

Covalent interact to amino functional groups present in surfaces, e.g. tissue surfaces (alkaline $\mathrm{pHs}$ )

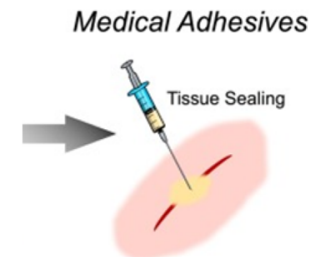

Fig. 1 Most typical DOPA adhesive and cohesive interactions found in mussel proteins, with singular emphasis in covalent interactions especially relevant for designing novel medical adhesives

limitation in quantity. However, the undesirable impurities caused by the bacterium E. coli during cell disruption and protein purification makes their use difficult; especially for medical and in vivo applications [23]. This highlights the need for developing new methods that allow to take full advantage of the adhesive properties found in mussels. In this way, the biomimicry - through the distillation of biological principles taking from the study of biological systems -is a highly promising and effective alternative of wet-adhesives innovation [24]. Also, a recent work has been focus on the generation of DOPA molecules on proteins surfaces by biocatalytic tyrosine oxidation [7].

Therefore, herein a novel strategy by chemical modification of proteins with DOPA molecules have been developed. For that purpose, L-DOPA methyl ester (DOPAME) was selected as catechol donor, with carboxyl group blocked, being the most similar to an oxidized tyrosine directly on the MAPS proteins. Lipase from Candida antartica fraction B (CAL-B) was selected as model protein, where its structure is well known and-also as an enzyme-it has hydrolytic activity which can be used as indirect way to determine the effect of the DOPA insertion.

The modification was carried out applying one of the most generic strategies focused on the incorporation of molecules, L-DOPAME in this case, on enzyme chemical groups $\left(\mathrm{COOH}\right.$ and $\left.\mathrm{NH}_{2}\right)$. Thus, considering the above, two strategies were followed (Scheme 1): firstly, a direct introduction of L-DOPAME over CAL-B carboxylic terminus residues, and secondly, a selective chemical incorporation of L-DOPAME to a modified tailor-made polymer for a subsequent coupling with CAL-B.

For this strategy, hyaluronic acid (HA) was used as matrix polymer. This is a well-known, widely studied polymer because of its interesting properties (biocompatible, biodegradable, nontoxic and non-immunogenic) [25]. It has been used as conjugate with different

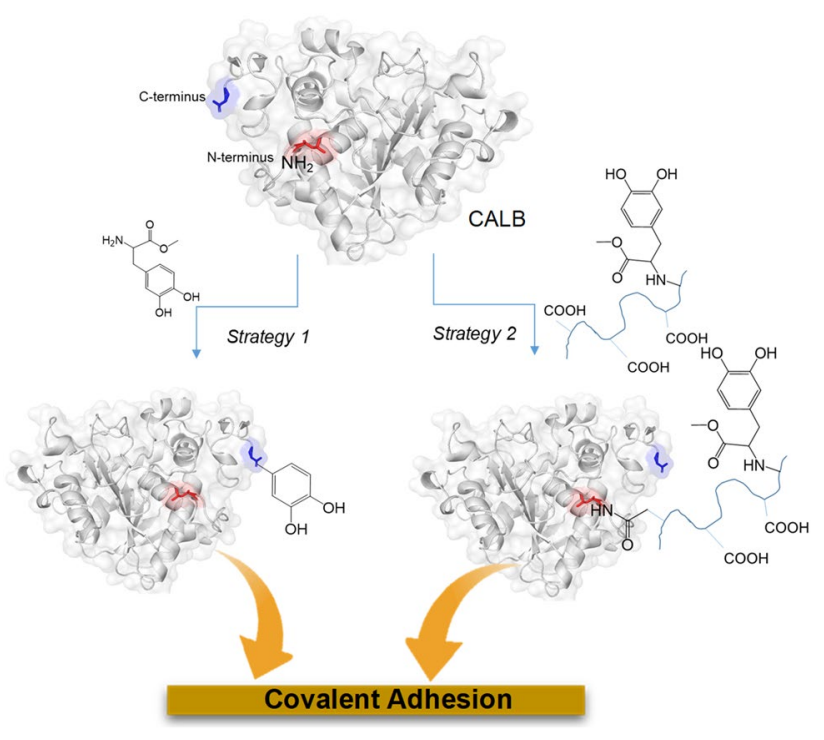

Scheme 1 General concept of protein modification strategy with DOPA molecules

enzymes in biomedical applications, such as therapeutic proteins [26]. Structurally, it is a glycopolymer based on a linear repetitive unit of a 1,4-disaccharide constituted by a glucuronic acid and a 2-acetamido-glucosamine units. Furthermore, this is a functionalized polymer because of the carboxylic group each disaccharide unit.

Finally, these new CAL-B modified enzymes were characterized, and the effect of the modification in their activity, thermostability and adhesion in Q-Sepharose support was evaluated.

Lipases are particular enzymes with a strong capacity for adhesion to hydrophobic interfaces because of the presence of large hydrophobic area in its open conformation $[27,28]$. Therefore, this confers a double 
adhesion capacity to these proteins by DOPA modification, which makes them very interesting as bioadhesives.

Consequently, this novel method could be an important starting point for the generation of new bio-adhesives on a commercial scale and competitive production cost with several applications in the medical and dental fields as well as in the wood industry. Moreover, this method could address some of the environmental concerns around production in the adhesive industry.

\section{Experimental section}

\subsection{Materials}

3,4-Dihydroxyphenylalanine methyl ester (L-DOPAME), tyrosine methyl ester, extra low molecular weight hyaluronic acid (HA, Mw $=8000-15,000 \mathrm{Da}), \mathrm{N}$-hydroxysuccinimide (NHS) and cellulose membrane dialysis tubing ( $\mathrm{Mw}$ cut-off $=14 \mathrm{~K}$ ) were purchased from Sigma-Aldrich (Spain). 1-Ethyl-3-(3-dimethylaminopropyl) carbodiimide (EDC) was purchased from Tokyo Kasei (Japan). A liquid formulation of lipase from C. antartica fraction B (CAL-B, $10 \mathrm{mg} /$ $\mathrm{mL}$ determined by Bradford assay) was from Novozymes. Bradford reagent (Pierce ${ }^{\mathrm{TM}}$ Coomassie Protein Assay Kit) was purchased from Thermo Scientific (Spain). Q-Sepharose ${ }^{\circledast} 4 B C L$ was purchased from GE Healthcare (Uppsala, Sweden). Centrifugation filters (Amicon ${ }^{\oplus}$ Ultra-4 mL, $10 \mathrm{~K}$ cut- off, $30 \mathrm{~K}$ cut-off) were purchased from Merck Millipore (Burlington, MA, USA), $p$-nitrophenyl propionate ( $p$-NPP) and sodium phosphate were purchased from SigmaAldrich (Saint Louis, MO, USA).

\subsection{Chemical modification of CAL-B with L-DOPA methyl ester}

Direct modification of CAL-B was carried out in six different reactions and a control solution, based on the L-DOPA methyl ester (L-DOPAME) and EDC content calculated as equivalents (eq) with respect to the enzyme (Table 1). For each reaction, 50,100 or 200 eq $(0.37 \mathrm{mg}, 0.74 \mathrm{mg}$, or $1.48 \mathrm{mg}$ respectively) of L-DOPAME were added to $1 \mathrm{~mL}$ of CAL-B in ultra-pure water solution $(1 \mathrm{mg} / \mathrm{mL}$ final concentration). After that, $\mathrm{pH}$ was adjusted to $4.8-5.0$, and a concentrated solution of EDC in ultra-pure water $(1 \mathrm{mg} / \mathrm{mL})$ was added. Three different EDC solution were prepared containing EDC from 5 eq (respect to DOPAME) or 10 eq (0.028, or $0.056 \mathrm{mg}$ respectively) and used immediately. After that, $\mathrm{pH}$ of solution was tested and adjusted again if it was necessary. The mixture was left overnight under constant stirring at room temperature. Then, each modified enzyme solution was dialyzed against ultra-pure water
Table 1 Different experimental conditions on preparing different DOPA-CALB proteins

\begin{tabular}{lccl}
\hline Protein & EDC (eq) & L-DOPA (eq) & $\begin{array}{l}\text { Final concen- } \\
\text { tration }(\mathrm{mg} / \\
\mathrm{ml})\end{array}$ \\
\hline CAL-B & 0 & 0 & 0.727 \\
CALB-DOPA-1 & 5 & 50 & 0.275 \\
CALB-DOPA-2 & 5 & 100 & 0.463 \\
CALB-DOPA-3 & 5 & 200 & 0.775 \\
CALB-DOPA-4 & 10 & 50 & 0.356 \\
CALB-DOPA-5 & 10 & 100 & 0.281 \\
CALB-DOPA-6 & 10 & 200 & 0.291 \\
\hline
\end{tabular}

$(4 \times 500 \mathrm{~mL})$ and the final concentrations were calculated following the Bradford method (Table 1) [29].

\subsection{Enzymatic activity assay}

The enzymatic activity was analysed spectrophotometrically at room temperature. The values were taken by measuring the increment in absorbance $(\lambda=348 \mathrm{~nm})$ produced by the release of $p$-nitrophenol ( $p N P, \varepsilon=5150 \mathrm{M}^{-1} \mathrm{~cm}^{-1}$ ) in the hydrolysis of pNPP $(50 \mathrm{mM})$ in sodium phosphate $(8.6 \mathrm{mg}, 25 \mathrm{mmol}, \mathrm{pH}$ 7). To initiate the reaction, $20 \mu \mathrm{L}$ of pNPP stock solution (prepared in acetonitrile) was added to $2.5 \mathrm{~mL}$ of phosphate buffer. Having done this, $20 \mu \mathrm{L}$ of the lipase solution or suspension was added under magnetic stirring. The initial rate was taking between 20 and $80 \mathrm{~s}$ of reaction. One unit of lipase activity (U) was defined as the amount of enzyme required to release $1 \mu \mathrm{mol}$ of pNP per minute under assay conditions. Specific activity was expressed as the activity units per mg of enzyme (U/ $\mathrm{mg})$.

\subsection{Thermostability assay}

The effect of temperature was assessed at $50{ }^{\circ} \mathrm{C}$ and $55^{\circ} \mathrm{C}$ under static conditions. For this, $20 \mu \mathrm{L}$ of sample were pulled, diluted, and tested for specific activity at period times ranging from $30 \mathrm{~min}$ to $1 \mathrm{~h}$. Activity retention was expressed as a fraction of retained activity relative to the initial activity of each sample. The activity was calculated by using the enzymatic assay described above.

\subsection{Preparation of hyaluronic acid (HA)-L-dopa methyl ester (DOPAME) polymer (HA-DOPA)}

Modification of HA was made based on the procedure described by Perez-Rizquez et al. [30] with modifications detailed as follows: Procedure 1: $30 \mathrm{mg}$ of HA were dissolved in $3.0 \mathrm{~mL}$ of distilled water at $\mathrm{pH} 5$ (final concentration 1\% HA). To this solution, $108 \mathrm{mg}$ of EDC and $96 \mathrm{mg}$ 
of NHS were added, and $\mathrm{pH}$ was adjusted between 5.05.5. HA activation was left in agitation for $1 \mathrm{~h}$. Following that, the $\mathrm{pH}$ was adjusted to 7.0 and L-DOPAME $(1.5 \mathrm{mg}$ or $3.0 \mathrm{mg}$ ) (for modification of $12.5 \%$ or $25 \%$ of polymer carboxylic groups, respectively) was poured into the solutions. The mixtures were left under continuous stirring overnight. For purification, centrifugation filters (Amicon ${ }^{\oplus}$ Ultra-4 mL, $10 \mathrm{~K}$ cut- off) were used, $2 \mathrm{~mL}$ of each solution was poured into the filters followed by $2 \mathrm{~mL}$ of ultra-pure water. Samples were centrifuged at $8000 \mathrm{rpm}$ for 5 min recovering $2 \mathrm{~mL}$ of sample. Following this, $2 \mathrm{~mL}$ of ultra-pure water was added again, and the solution was centrifuged for a second time. This procedure was then repeated once more. Two different new polymer solutions were obtained: HA-DOPA-12.5 and HA-DOPA-25.

\subsection{Preparation of Hyaluronic Acid (HA)-L-tyrosine methyl ester polymer (HA-TYR)}

Different HA Polymers modified using tyrosine methyl ester (TYRME) instead DOPAME was performed using the same synthetic protocol described above, obtaining the new polymers named HA-TYR-12.5 and HA-TYR- 25 .

\subsection{CALB conjugation with HA-DOPA polymers}

First, free carboxylic groups of HA-DOPAME polymer were activated by EDC/NHS protocol. 5, 25 and 50 equiv of polymers were added to CAL-B solution $(1 \mathrm{mg} / \mathrm{mL}$ in distilled water). For that, $0.25 \mathrm{~mL}$ (5 eqv), $1.42 \mathrm{~mL}$ ( $25 \mathrm{eq}$ ) and $2.85 \mathrm{~mL}$ (50 eq) of HA (control), HA-DOPA-12.5 and HA-DOPA-25 polymers were activated adding 5 eq of solid EDC ( $0.15 \mathrm{mg}, 0.85 \mathrm{mg}$ and $1.7 \mathrm{mg})$ and 10 eq of NHS $(0.2 \mathrm{mg}, 1 \mathrm{mg}$ and $2 \mathrm{mg}$ ) in each solution and incubation for $1 \mathrm{~h}$. After this activation time, $1 \mathrm{~mL}$ of CAL-B aqueous solution $(1 \mathrm{mg} / \mathrm{mL})$ was added to polymer solutions and after, an adjustment of 7.0 in the $\mathrm{pH}$ was performed in each case. The mixture was left under continuous stirring overnight. After that, purification was performed using centrifugation filters (Amicon ${ }^{\circledast}$ Ultra- $4 \mathrm{~mL}, 30 \mathrm{~K}$ cutoff), washing 2 times with distilled water for a complete removal of the free polymer. The final concentration of the pure sample was around $1 \mathrm{mg} / \mathrm{ml}$ protein. The new proteins were named CALB-HA-5, CALB-HA-50, CALBHA-DOPA-1 2.5-5, CALB-HA-DOPA-25-5, CALB-HADOPA-25-25, CALB-HA-DOPA-25-50.

\subsection{Adhesion experiment: adsorption on Q-Sepharose support}

$300 \mu \mathrm{L}$ of different enzyme solutions were dissolved in $3 \mathrm{~mL}$ of $5 \mathrm{mM} \mathrm{NaH} \mathrm{PO}_{4}$ buffer, $\mathrm{pH}$ 8.5. An aliquot of $100 \mu \mathrm{L}$ was collected (control solution). Then, $100 \mathrm{mg}$ of
Q-Sepharose was added to each solution. The $\mathrm{pH}$ was adjusted to 8.5 if it was necessary. After that, the suspensions were stirred for $2 \mathrm{~h}$ at room temperature. Periodically, $60 \mu \mathrm{L}$ of sample were withdrawn, centrifuged and the enzyme activity of the supernatant was measured in the pNPP assay.

\subsection{Circular dichroism}

Circular dichroism (CD) spectra of the different CALB-DOPA and CALB-HA-DOPA conjugated proteins were recorded in a Chirascan spectropolarimeter (Applied Photophysics) at $25( \pm 1){ }^{\circ} \mathrm{C}$. Near-UV spectra were recorded at wavelengths between 250 and $310 \mathrm{~nm}$ in a $1 \mathrm{~cm}$ path-length cuvette and Far-UV spectra were recorded at wavelengths between 200 and $260 \mathrm{~nm}$ in a $0.1 \mathrm{~cm}$ path-length cuvette. Protein concentrations were 20 and $10 \mu \mathrm{M}$ respectively in phosphate buffered saline, pH 7.2 (PBS; bioMerieux).

\subsection{Fluorescence spectroscopy}

Fluorescence measurements of the different CALBDOPAME and CALB-HA-DOPA conjugated proteins were performed in a Varian Cary Eclipse Fluorescence Spectrophotometer (Agilent Technologies) monitoring the intrinsic tryptophan fluorescence in $2 \mu \mathrm{M}$ of each protein, using an excitation wavelength of $280 \mathrm{~nm}$, with excitation and emission bandwidths of $5 \mathrm{~nm}$, and recording fluorescence emission spectra between 300 and $400 \mathrm{~nm}$. All spectroscopic measurements were made in water.

\subsection{MALDI-TOF spectra}

MALDI-MS spectra of the different CALB-DOPA and CALBHA-DOPA conjugated proteins were recorded in a Bruker MicroFlex (Bruker Daltonics) by using 3-5-Dimethoxy4-hydroxycinnamic acid (Sinapinic acid) as matrix. $1 \mu \mathrm{L}$ of pure protein sample were mixed with $1 \mu \mathrm{L}$ of a saturated sinapinic solution (50:50 water/acetonitrile with $0.01 \%$ TFA final concentration). The mixture was spotted onto the surface of a stainless steel MALDI target and dried at ambient temperature.

\section{Results and discussion}

\subsection{Direct chemical modification of CAL-B with DOPA molecules}

The first strategy was based on the chemical incorporation of DOPA molecules directly on the protein surface (Fig. 2). The protein modification was carried out on the carboxylic 


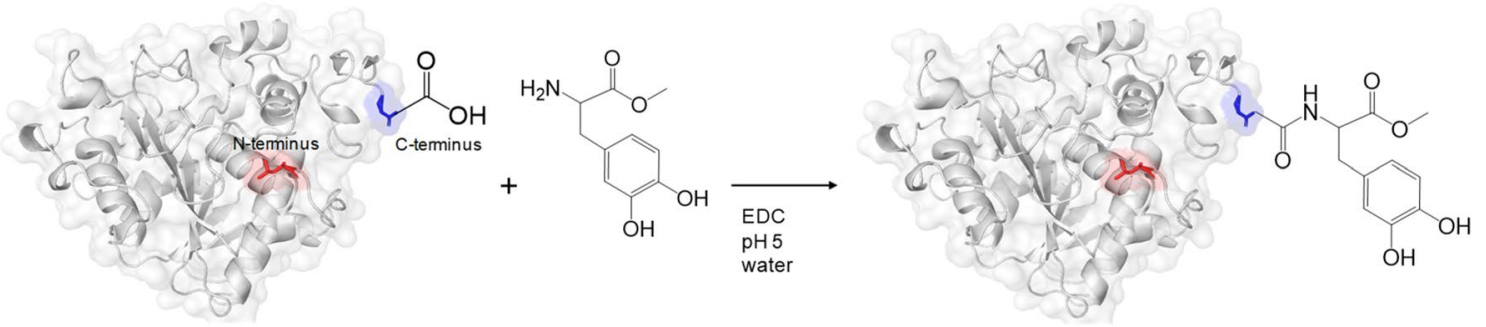

Fig. 2 Chemical Modification of C-terminus of CAL-B with L-DOPAME in aqueous media, r.t. (The pdb code for CAL-B 3D-structure is TCA)

Table 2 Specific enzymatic activity of the different CALB-DOPA proteins in the hydrolysis of pNPP

\begin{tabular}{lr}
\hline Protein & \multicolumn{1}{l}{$\begin{array}{l}\text { Specific } \\
\text { Activity } \\
\text { mg) }(U /\end{array}$} \\
\hline CAL-B & $9.03 \pm 0.45$ \\
CALB-DOPA-1 & $19.6 \pm 0.98$ \\
CALB-DOPA-2 & $11.51 \pm 0.58$ \\
CALB-DOPA-3 & $6.69 \pm 0.33$ \\
CALB-DOPA-4 & $20.93 \pm 1.04$ \\
CALB-DOPA-5 & $25.55 \pm 1.27$ \\
CALB-DOPA-6 & $19.36 \pm 0.97$ \\
\hline
\end{tabular}

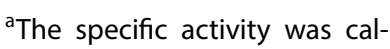
culated at $25^{\circ} \mathrm{C}$ as described in experimental part

groups on the surface, especially in the $C$-terminus, the most reactive carboxylic group on the protein.

The modification was attempted by six different conditions, in which the amount of water-soluble carbodiimide (EDC) as activator of the carboxylic group, and the amount of amino acid (DOPAME) was varied (Table 1). To control the selectivity of the modification and avoid non-specific cross reactions between protein molecules, a low amount of EDC was used (5 or 10 eq with respect to the protein) and the reaction was carried out around $\mathrm{pH} 4.8$ in distilled water. The amino acid was added in clear excess to ensure chemical modification using 50 to 200 eq [31].

To evaluate the success of the modification, the specific hydrolytic activity of CALB was performed for the six different modified proteins (CALB-DOPA1-6) (Table 2).

The results showed that the modification protocol clearly affected the enzyme activity in the hydrolysis of $p$-nitrophenyl propionate. In most cases, the specific activity of the enzyme improved after DOPA modification compared to the activity of native CAL-B (Table 2). In particular, the CALB-DOPA-1,4, 5 and $\mathbf{6}$ proteins showed more than 2 times more activity than the unmodified enzyme. Using the least amount of DOPAME (50 eq) with the highest amount of EDC tested (10 eq) appeared to be the best option in terms of improvement activity, from 9 IU for CALB to 25 IU for CALB-DOPA-5 (Table 2).
Far circular dichroism (CD) experiments were performed to study the effect of modification on secondary structure and near CD and fluorescence assays to analyze the effect on tertiary structure (Fig. 3). According to the far CD spectrum, the content of the a helix secondary structure in CAL-B decreased in all cases after DOPA modification due to variations in the strong negative bands with two peaks, at $\sim 208$ and $\sim 222 \mathrm{~nm}$, and in the very positive band at $\sim 200 \mathrm{~nm}$, being the most intense differences observed in CALB-DOPA-5, CALB-DOPA-1 and CALB-DOPA-6, which also showed the best increase in activity (Fig. 3a). Small differences like this have been observed previously in the modification of this enzyme using a glycomolecule, where also improvements of activity were observed [32]. However, near CD and fluorescence spectra did not show significant differences between native CALB and DOPAmodified proteins. These results demonstrated that CALB was modified and this small modification did not affect to the tertiary structure or, more precisely, the environment of the protein aromatic residues (which are responsible for the signal detected by these spectroscopic techniques) seems unaltered.

In addition, modifications were made by these six strategies using tyrosine methyl ester (TYRME) instead of DOPAME were performed and similar results were obtained (Figure S1).

The thermostability of proteins is another important factor. At this point the effect on the stability of the lipase by DOPA incorporation was evaluated at two different temperatures ( 50 and $55^{\circ} \mathrm{C}$ ) (Table 3, Figure S2), where CALB suffers relative fast inactivation [32].

Native CALB retained $55 \%$ activity at $50{ }^{\circ} \mathrm{C}$ after $4 \mathrm{~h}$, while only $13 \%$ was preserved after $1 \mathrm{~h}$ incubation at $55^{\circ} \mathrm{C}$ (Table 3 ). The stability of CALB modified with DOPA molecules was also affected by the binding conditions. The addition of a greater amount of aminoacid improved the stability, although surprisingly the 200 eq strategy (CALB-DOPA-3 and 6) caused a negative effect similar to that observed in the activity values. The amount of EDC in the chemical reaction seems to be important, since an improvement in stability at 

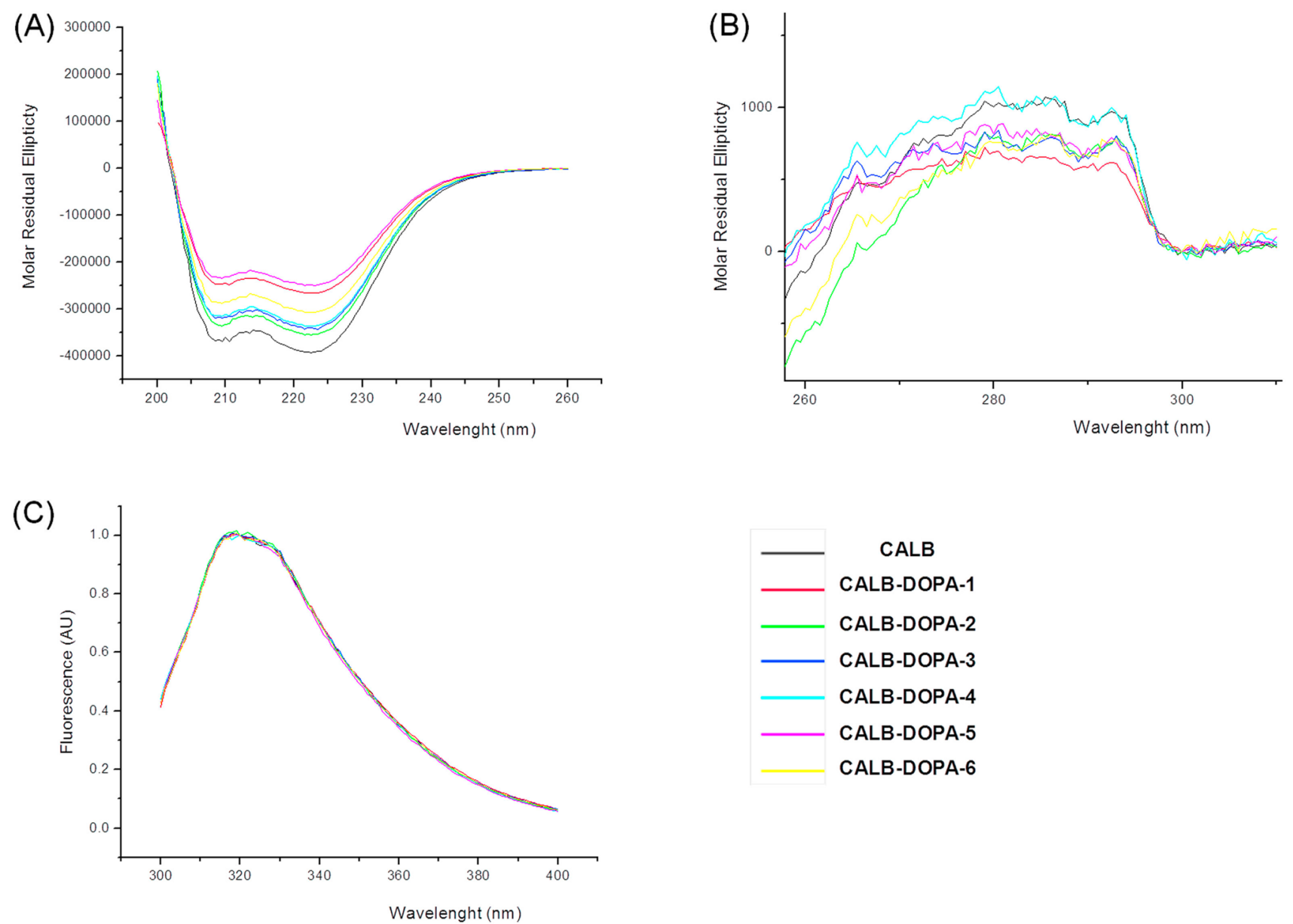

Fig. 3 Characterization of different CALB-DOPA modified proteins. a CD Far-UV spectra. b CD Near-UV spectra. $\mathbf{c}$ Fluorescence spectra

Table 3 Thermostability of different CALB-DOPA proteins

\begin{tabular}{lll}
\hline Protein & $\begin{array}{l}\text { Residual activity } \\
50^{\circ} \mathrm{C} 4 \mathrm{~h}(\%)\end{array}$ & $\begin{array}{l}\text { Residual activity } \\
\text { at } 55^{\circ} \mathrm{C} 1 \mathrm{~h} \mathrm{( \% )}\end{array}$ \\
\hline CAL-B & 55 & 13 \\
CALB-DOPA-1 & 53 & 9 \\
CALB-DOPA-2 & 90 & 5 \\
CALB-DOPA-3 & 30 & 26 \\
CALB-DOPA-4 & 62 & 14 \\
CALB-DOPA-5 & 70 & 50 \\
CALB-DOPA-6 & 40 & 11 \\
\hline
\end{tabular}

${ }^{\mathrm{a}}$ The residual activity was calculated in comparison with the activity of each protein at $25^{\circ} \mathrm{C}$

$50{ }^{\circ} \mathrm{C}$ was observed using 50 and 100 eq of aminoacid when 10 eq EDC were used (CALB-DOPA-4 and 5), although the greatest stabilization it was achieved in the case of CALB-DOPA-2, which conserved $90 \%$ of the initial activity after $4 \mathrm{~h}$ of incubation (Table 3 ). At $55^{\circ} \mathrm{C}$ incubation, only the CALB-DOPA-5 protein showed a clear improvement in stability, retaining $50 \%$ of activity after $1 \mathrm{~h}$, with a half live 4 times longer than the native CALB (Figure S2).

Finally, analysis of the modified DOPA proteins by MALDI-TOF mass spectrometry was performed in order to know exactly the number of DOPAME molecules incorporated per molecule of protein. In this sense, Fig. 4 shows the MALDI spectra of two DOPA proteins, CALBDOPA-5 and CALB-DOPA-2.

In both cases, the observed exact mass for the DOPAproteins $[M=34,653.2500]$ or $[M=34,615.6992]$ corresponded approximately to the modification of CALB with a molecule of DOPAME [calculated $M=34,704,67$, presumably in the C-terminus (Fig. 2). 
(A)

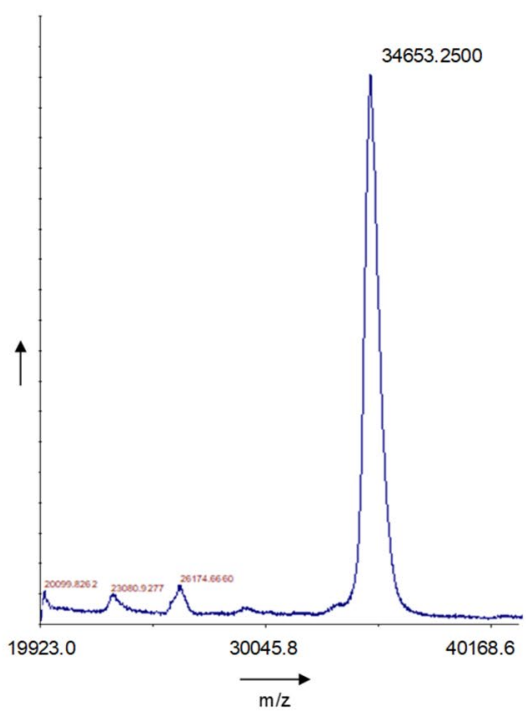

(B)

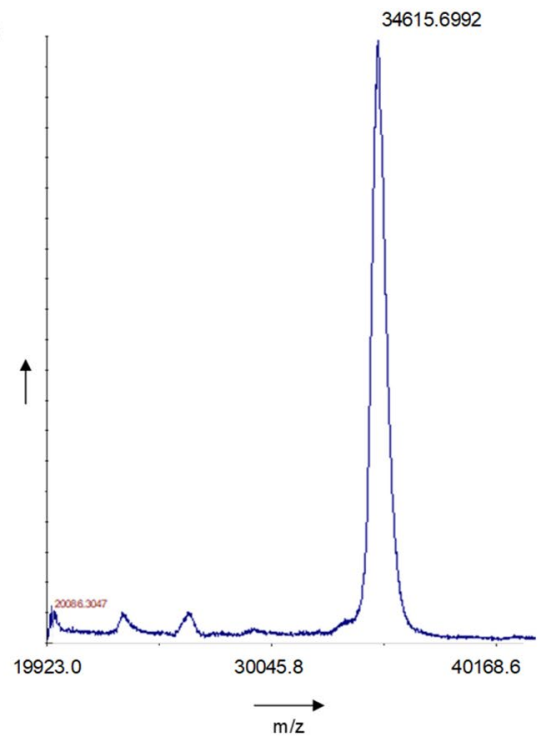

Fig. 4 MALDI-TOF Spectra. a CALB-DOPA-2 protein. b CALBDOPA-5 protein. The number of modifications was calculated based on the observed molecular mass of the native CALB mass (M: $[34,467])$

\subsection{Chemical modification of CAL-B with DOPA-functionalized polymers}

\subsubsection{Synthesis of tailor-made hyaluronic Acid (HA)-DOPA polymers}

For a second approach in order to introduce several DOPA molecules at the same time, the preparation of tailor-made hyaluronic acid (HA) functionalized with DOPA molecules was attempted (Fig. 5).

Thus, some of the carboxylic groups were modified by introducing DOPA molecules, leaving others free for later insertion into the protein. In this way, two different

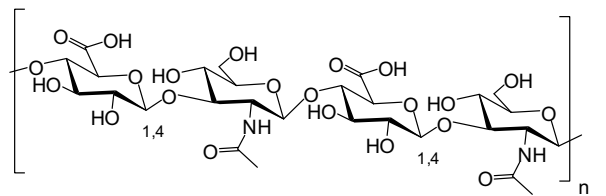

HA $\mathrm{pH} 5 \downarrow \begin{aligned} & \mathrm{EDC} / \mathrm{NHS} \\ & 1 \mathrm{~h}\end{aligned}$
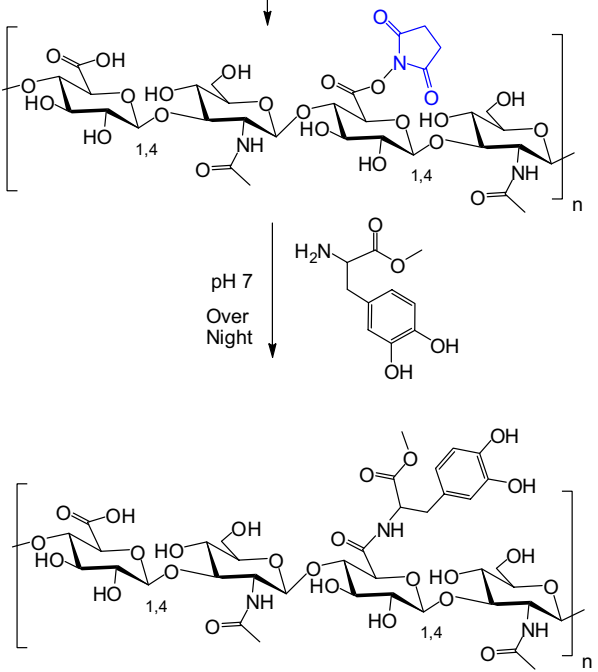

HA-DOPA

Fig. 5 General scheme of the chemical preparation of HA-DOPA polymers

polymers were prepared, with a degree of modification of $12.5 \%$ or $25 \%$ of the total carboxylic groups of the polymer. The methodology was again the EDC/NHS activation at $\mathrm{pH}$ 5 of the HA for $1 \mathrm{~h}$ and after the addition of L-DOPAME, which was used as the DOPA unit (Fig. 5). Two different polymers named HA-DOPA-12.5 and HA-DOPA-25 were obtained respectively. The presence of DOPA molecule in the different polymers was confirmed by FTIR experiments (Figure S3). The same strategy was used, changing DOPAME by TYRME in order to synthesize new HA-TYR polymers (Figure S4).

\subsubsection{Conjugation of CALB with HA-DOPA polymers}

The synthesis of a new type of DOPA proteins by the selective modification of CALB with new HA-DOPA polymers is described in Fig. 6 . The first step was the prior activation of the free $\mathrm{COOH}$ groups in the functionalized HA-DOPA polymers. In order to control a selective modification of the amino groups of the proteins, particularly in the N-terminus - the most reactive one-, the activation of only a few groups was performed, by using low amount of EDC (5 eq). This activation was carried out in the presence of NHS to obtain isolated stable activated polymers (Fig. 6). Then the CALB modification was only done by adding 


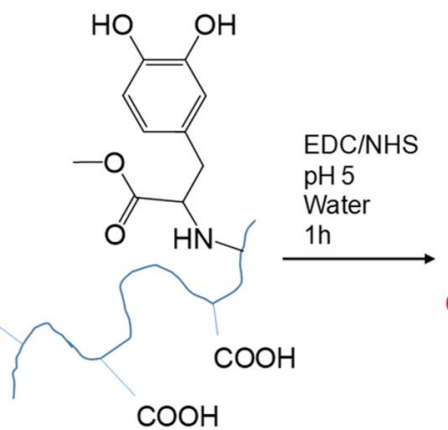

HA-DOPAME polymers<smiles>COC(=O)C(Cc1ccc(O)c(O)c1)NC(C)CC(CCCCC(C(=O)O)C(=O)O)C(=O)O</smiles>

Activated HA-DOPAME polymers

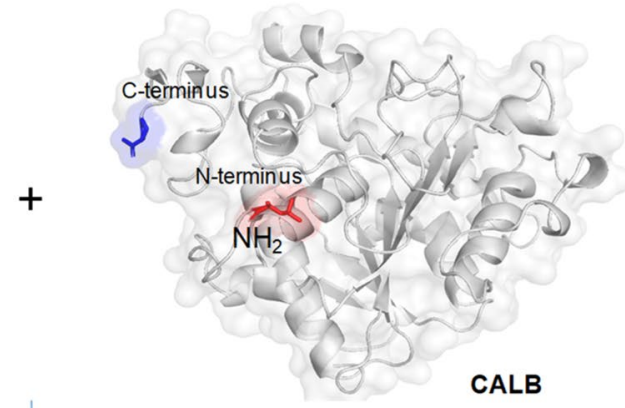

$\mathrm{pH} 7$ water

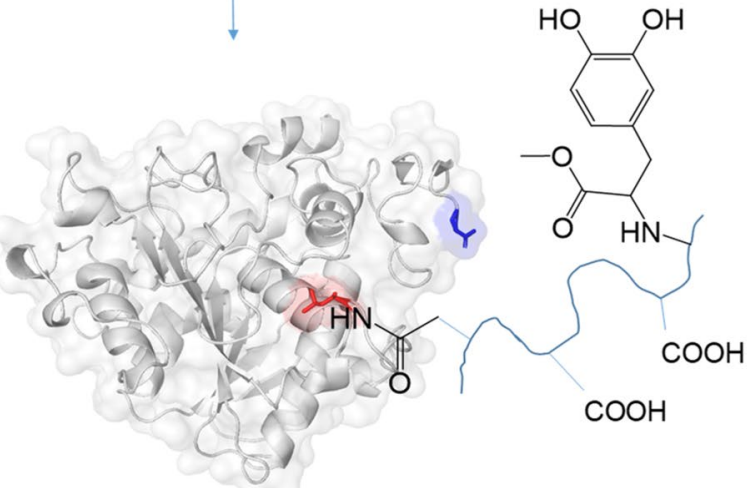

Fig. 6 Synthesis of novel CALB-HA-DOPA proteins by conjugation of CALB with tailor-made HA-DOPA polymers (The pdb code for CAL-B $3 \mathrm{D}$-structure is TCA)

the polymer adjusting the $\mathrm{pH}$ to 7 . At this point, initially 5 equiv. of polymer (HA-DOPA-12.5 and HA-DOPA-25) per protein molecule were used. Furthermore, a modification of CALB was performed using HA (as control polymer) or HA-TYR (as control aminoacid-functionalized polymer) polymers under the same conditions.

However, the analysis of Far CD and fluorescence spectroscopy spectra of the different modified proteins suggested that no significant alterations on their structure were found compared to the native enzyme (Figure S5-S6). These results suggested that three-dimensional structure of the protein has not changed significantly and remains similar to the native protein. Therefore, an increase in the amount of polymer was applied to 50 equivalents per molecule of CALB. In this case, the HA-DOPA-25 was used, producing the so-called CALB-HA-DOPA-25-50. The specific activity of the enzyme after polymer modification increased approximately 2 -fold mainly due to the polymer (Table 4). The thermostability of the enzyme was also preserved after incorporation of the polymer (Table 4).

Near circular dichroism (CD) and fluorescence spectroscopy assays were performed to determine changes in tertiary structure (Fig. 7). According to Near CD, the CAL-B spectrum after the modification process with
Table 4 Specific activity and thermostability of the different CALBDOPA proteins in PNPP hydrolysis

\begin{tabular}{lcl}
\hline Protein & $\begin{array}{l}\text { Specific }^{\mathrm{mg})} \\
\text { activity }^{\mathrm{a}}(\mathrm{U} /\end{array}$ & $\begin{array}{l}\text { Residual } \\
\text { activity at } \\
50{ }^{\circ} \mathrm{C}(\%)\end{array}$ \\
\hline CALB & 9 & 55 \\
CALB-HA & 26 & 52 \\
CALB-HA-DOPA-25-50 & 17 & 53 \\
\hline
\end{tabular}

a The specific activity was calculated at $25^{\circ} \mathrm{C}$ as described in experimental part

${ }^{\mathrm{b}}$ The residual activity was calculated in comparison with the activity of each protein at $25^{\circ} \mathrm{C}$ after $4 \mathrm{~h}$ incubation at $50^{\circ} \mathrm{C}$

HA-DOPA-25 (CALB-HA-DOPA-25-50), lost almost all its signal (Fig. 7a). Furthermore, the fluorescence spectrum of the modified protein exhibited a $9 \mathrm{~nm}$ shift from its maximum (from 325 to $316 \mathrm{~nm}$ ) (Fig. 7b). Both spectroscopy findings suggested that the presence of the polymer strongly altered the tertiary structure of the enzyme. Structural analysis of HA-TYR polymer modified CALB showed similar alterations in tertiary structure (Figure S7). 

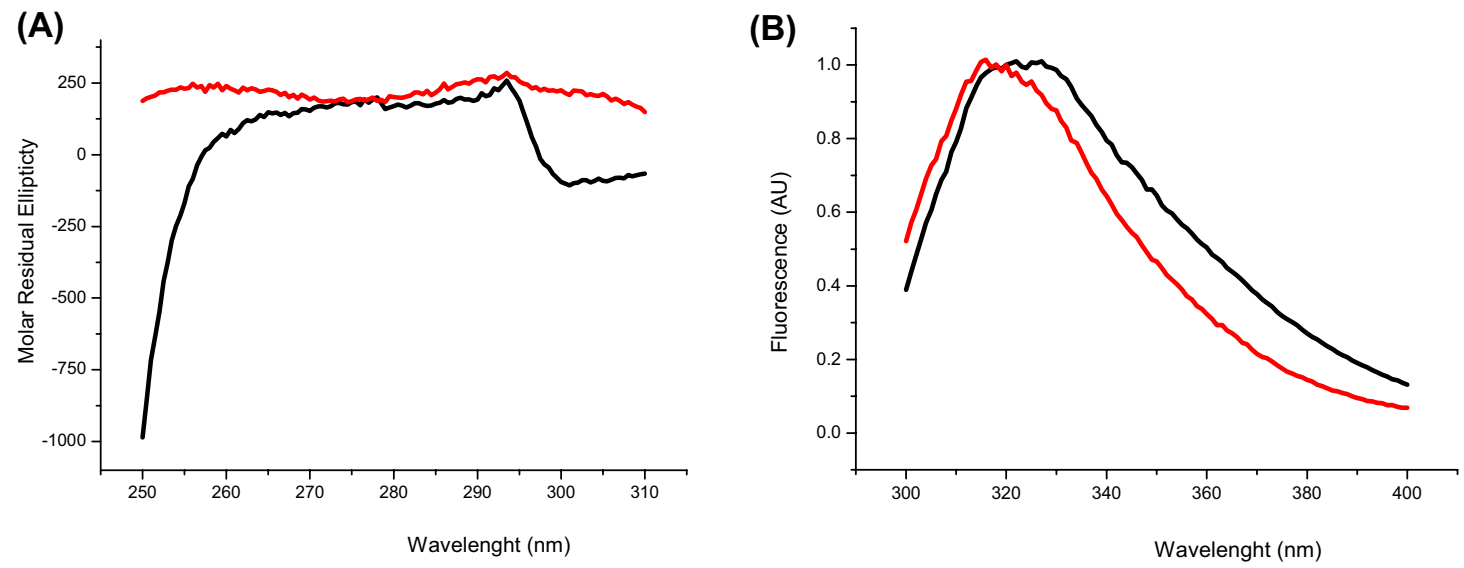

Fig. 7 Characterization of different CALB-HA-DOPA-25-50 protein. a CD Far-UV spectra. b Fluorescence spectra. CALB-HA-DOPA-25-50 (red), CALB (black)

\subsection{Covalent adhesion of CALB-DOPA proteins on functionalized amino-surface}

Finally, to demonstrate the selective adhesion capacity of the new DOPA proteins, the covalent adhesion experiment on Q-Sepharose an amino functionalized support, was selected (Fig. 8). This support was selected because we had observed in previous work that CALB does not adsorb on this support even at high $\mathrm{pH}(\mathrm{pH}$ 8.5) [33]. Thus, this represents an excellent example to evaluate the efficiency of the incorporation of DOPA molecule at CALB.

Therefore, the different synthesized CALB proteins and CALB and CALB-HA as control were incubated with Q-Sepharose in $5 \mathrm{mM}$ phosphate buffer at pH 8.5 (Fig. 8). After 30 min incubation, $40 \%$ of CALB-DOPA-5 was covalently attached to the solid support, whereas in the case of CALB-HA-DOPA-25-50 the adhesion speed was lower (around 20\%) (Fig. 8b). At this time, no adherence was observed to CALB and very slight was observed for the other CALB proteins modified with HA or HA-TYR (5\%) (Fig. 8). The trend was similar adherence of $90 \%$ was achieved with CALB-DOPA-5 at $60 \mathrm{~min}$, which fully adhered after $90 \mathrm{~min}$. The CALB-HA-DOPA-25-50 was also completed bound to the solid after $90 \mathrm{~min}$. CALB was still all in the supernatant and the rest just bound a bit more (around 15\%) (Fig. 8). Therefore, this clearly demonstrates a new strategy to introduce DOPA molecules in order to create a large amount of mussel-inspired adhesive proteins.

\section{Conclusions}

A new methodology for the preparation of DOPA functionalized proteins has been described. Two strategies were followed, direct conjugation of DOPA at the C-terminus
(A)

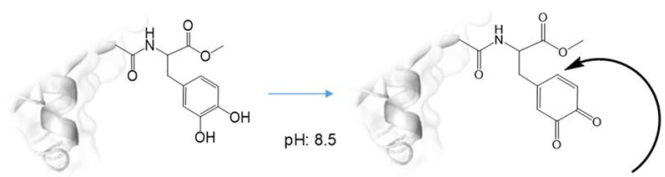

DOPAmodified proteins

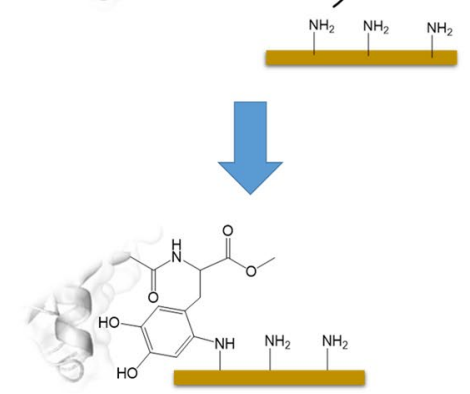

(B) Specific Covalent Adhesion

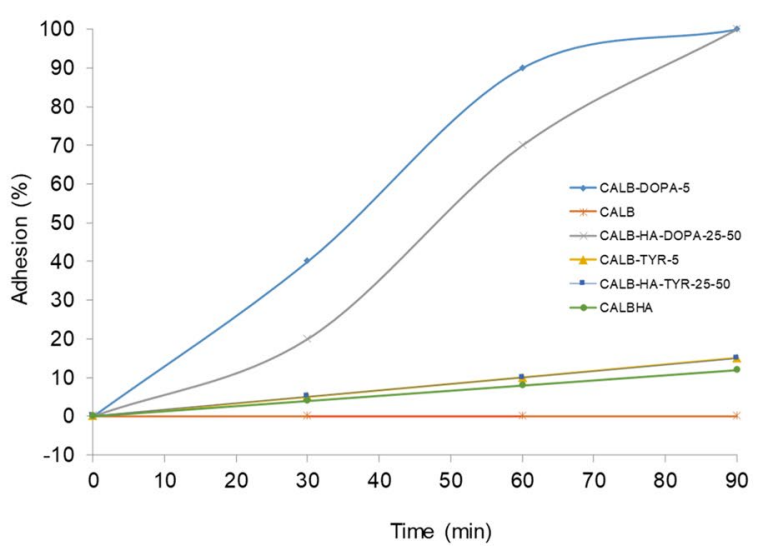

Fig. 8 Experiment of covalent adhesion of CALB-DOPA proteins on amino functionalized surface. a Scheme of the covalent attachment of modified proteins by catechol moiety on surface. b Covalent adsorption of CALB proteins on Q-Sepharose at $\mathrm{pH} 8.5$ in aqueous media

\section{SN Applied Sciences}


on the surface of the protein, and protein conjugation with tailor-made glycopolymers (DOPA-hyaluronic acid (HA) polymers) at the $\mathrm{N}$-terminus. The insertion of DOPA into CALB was found to increase the thermostability of the protein.

The selectively covalent adhesion of these artificial proteins on the amino-functionalized surface was exclusively due to the presence of the DOPA moiety. This is a critical role, which is crucial for the efficiency of MAPS, so it could open the alternative application of these proteins as artificial bioadhesives.

Furthermore, it seems that direct insertion of the DOPA molecule worked better than using a polymer chain as a linker, probably because in the latter there could be possible covalent interactions between aromatic rings on the surface of the protein around the $\mathrm{N}$-terminus and the catechol groups in the polymer (Figure S8). For example, this interaction could have influence on the final location of the polymer and also affecting insertion. At this point, further research needs to be done to find a way to obtain the highest adhesion capacity by using this glycopolymer strategy.

Acknowledgements This work was supported by the Spanish National Research Council (CSIC), Fondo de Investigaciones Sanitarias from Instituto de Salud Carlos III, and European Union (ERDF/ ESF, 'Investing in your future') (PI15/00663 and PI18/00349 to OA); Diputación General de Aragón (Translation Research group in Digestive Pathology Group_E25_17R to OA); and Centro de Investigación Biomédica en Red en Enfermedades Hepáticas y Digestivas (CIBERehd). The authors thank the COST Action CA15216 (ENBA) for COST meeting support. We also thank Dr. Martinez from Novozymes and Proteomics Facility of Servicios Científico Técnicos del CIBA (IACS-Universidad de Zaragoza), ProteoRed ISCIII, Zaragoza, Spain.

\section{Compliance with ethical standards}

Conflict of interest The authors declare no competing financial interest.

\section{References}

1. Petrie EM (2007) Handbook of adhesives and sealants, 2nd edn. McGrawHill, New York

2. Dinte E, Sylvester B (2017) Adhesives: applications and recent advances. In: Özer H (ed) Applied adhesive bonding in science and technology. IntechOpen, Londrina. https://doi.org/10.5772/ intechopen.71854

3. Ebnesajjad S (2009) Adhesives technology handbook. William Andrew, New York

4. Guo Q, Chen J, Wang J, Zeng H, Yu J (2020) Recent progress in synthesis and application of mussel-inspired adhesives. Nanoscale 12:1307-1324

5. Lu D, Wang H, Li T, Li Y, Dou F, Sun S, Guo H, Liao S, Yang Z, Wei Q, Lei Z (2017) Mussel-inspired thermoresponsive polypeptidepluronic copolymers for versatile surgical adhesives and hemostasis. ACS Appl Mater Interfaces 9:16756-16766
6. Quan W-Y, Hu Z, Liu H-Z et al (2019) Mussel-inspired catecholfunctionalized hydrogels and their medical applications. Molecules 24:2586

7. Sogawa H, Ifuku N, Numata K (2019) 3,4-Dihydroxyphenylalanine (DOPA)-containing silk fibroin: its enzymatic synthesis and adhesion properties. ACS Biomater Sci Eng 5:5644-5651

8. Favi PM, Yi S, Lenaghan SC, Xia L, Zhang M (2014) Inspiration from the natural world: from bio-adhesives to bio-inspired adhesives. J Adv Sci Technol 28:290-319

9. Norström E, Demircan D, Fogelström L, Khabbaz F, Malmström E (2017) Green binders for wood adhesives. In: Özer H (ed) Applied adhesive bonding in science and technology. IntechOpen, Londrina. https://doi.org/10.5772/intechopen.72072

10. Stewart RJ, Ransom TC, Hlady V (2011) Natural underwater adhesives. J Polym Sci Part B Polym Phys 49:757-771

11. Zhao Y, Wu Y, Wang L, Zhang M, Chen X, Liu M, Wang Z (2017) Bio-inspired reversible underwater adhesive. Nat Commun 8:2218

12. Mehdizadeh M, Yang J (2013) Design strategies and applications of tissue bioadhesives. Macromol Biosci 13:271-288

13. Hwang DS, Zeng $\mathrm{H}$, Masic $A$, Harrington MJ, Israelachvili JN, Waite JH (2010) Protein- and metal-dependent interactions of a prominent protein in mussel adhesive plaques. J Biol Chem 285:25850-25858

14. Choi BH, Cheong H, Ahn JS, Zhou C, Kwon JJ, Cha HJ, Jun SH (2015) Engineered mussel bioglue as a functional osteoinductive binder for grafting of bone substitute particles to accelerate in vivo bone regeneration. J Mater Chem B 3:546-555

15. Deming TJ (1999) Mussel byssus and biomolecular materials. Curr Opin Chem Biol 3:100-105

16. Song W-K, Kang J-H, Cha J-K et al (2018) Biomimetic characteristics of mussel adhesive protein-loaded collagen membrane in guided bone regeneration of rabbit calvarial defects. J Period Implant Sci 48:305-316

17. Yu M, Hwang J, Deming TJ (1999) Role of I-3,4-dihydroxyphenylalanine in mussel adhesive proteins. J Am Chem Soc 121:5825-5826

18. Forooshani PK, Lee BP (2016) Recent approaches in designing bioadhesive materials inspired by mussel adhesive protein. J Polym Sci Part A Polym Chem 55:9-33

19. Israelachvili JN, Waite JH, Butler A, Rapp MV, Maier GP (2015) Adaptive synergy between catechol and lysine promotes wet adhesion by surface salt displacement. Science 349:628-632

20. Yu J, Wei W, Danner E, Israelachvili JN, Waite JH (2011) Effects of interfacial redox in mussel adhesive protein films on mica. Adv Mater 23:2362-2366

21. Strausberg RL, Link RP (1990) Protein-based medical adhesives Trends Biotechnol 8:53-57

22. Hyung Joon C, Dong Soo H, Seonghye L (2008) Development of bioadhesives from marine mussels. Biotechnol J 3:631-638

23. Hwang DS, Gim Y, Yoo HJ, Cha HJ (2007) Practical recombinant hybrid mussel bioadhesive fp-151. Biomaterials 28:3560-3568

24. Hwang J, Jeong Y, Park JM, Lee KH, Hong JW, Choi J (2015) Biomimetics: forecasting the future of science, engineering, and medicine. Int J Nanomed 10:5701-5713

25. Larrañeta E, Henry M, Irwin NJ, Trotter J, Perminova AA, Donnelly RF (2018) Synthesis and characterization of hyaluronic acid hydrogels crosslinked using a solvent-free process for potential biomedical applications. Carbohydr Polym 181:1194-1205

26. Wolf KJ, Kumar S (2019) Hyaluronic acid: incorporating the bio into the material. ACS Biomater Sci Eng 5:3753-3765

27. Smith LC, Faustinella F, Chan L (1992) Lipases: three-dimensional structure and mechanism of action. Curr Opin Struct Biol 2:490-496

28. Fernández-Lorente G, Cabrera Z, Godoy C, Fernandez-Lafuente R, Palomo JM, Guisan JM (2008) Interfacially activated Lipases 
against hydrophobic supports: effect of the support nature on the biocatalytic properties. Process Biochem 43:1061-1067

29. Bradford MM (1976) A rapid and sensitive method for the quantitation of microgram quantities of protein utilizing the principle of protein-dye binding. Anal Biochem 72:248-254

30. Perez-Rizquez C, Lopez-Tejedor D, Plaza-Vinuesa L, de las Rivas B B, Muñoz R, Cumella J, Palomo JM (2019) Chemical modification of novel glycosidases from Lactobacillus plantarum using hyaluronic acid: effects on high specificity against 6-phosphate glucopyranoside. Coatings 9:311

31. Perez-Rizquez C, Abian O, Palomo JM (2019) Site-selective modification of tryptophan and protein tryptophan residues through PdNP bionanohybrid-catalysed $\mathrm{C}-\mathrm{H}$ activation in aqueous media. Chem Commun 55:12928-12931
32. Gutarra ML, Romero O, Abian O, Torres FAG, Freire DMG, Castro AM, Guisan JM, Palomo JM (2011) Enzyme surface glycosylation on the solid phase: improve activity and selectivity of Candida antarctica lipase B. ChemCatChem 3:1902-1910

33. Filice M, Romero O, Guisan JM, Palomo JM (2011) Trans, trans2,4-Hexadiene incorporation on enzymes for site-specific immobilization and fluorescent labeling. Org Biomol Chem 9:5535-5540

Publisher's Note Springer Nature remains neutral with regard to jurisdictional claims in published maps and institutional affiliations. 